10

\title{
Светосильный двухкристальный акустооптический монохроматор
}

\author{
( М.М. Мазур, ${ }^{1}$ Л.И. Мазур, ${ }^{1}$ В.И. Пустовойт, ${ }^{1,2}$ Ю.А. Судденок, ${ }^{1}$ В.Н. Шорин ${ }^{1}$ \\ ${ }^{1}$ Всероссийский научно-исследовательский институт фризико-технических и радиотехнических измерений, \\ 141570 Менделеево, Московская обл., Россия \\ ${ }^{2}$ Научно-технологический центр уникального приборостроения РАН, \\ 117342 Москва, Россия \\ e-mail: s-mmazur@mail.ru
}

(Поступило в Редакцию 5 октября 2016 г. В окончательной редакции 27 декабря 2016 г.)

Приведены результаты разработки и исследований двухкристального светосильного акустооптического монохроматора. Показано, что использование отражения света от одной из граней акустооптической ячейки в качестве разводящего поляризатора может существенно повысить коэффициент передачи монохроматора и упростить его конструкцию. Найдены области параметров акустооптического взаимодействия (области углов и длин волн), в которых такие монохроматоры эффективны. Получены характеристики двух светосильных акустооптических монохроматоров с различным значением параметров акустооптического взаимодействия.

DOI: 10.21883/JTF.2017.09.44917.2056

\section{Введение}

Двойные акустооптические монохроматоры (АОМ), в которых происходит последовательная дифракция светового излучения, в отличие от одинарных обладают целым рядом достоинств: резкое подавление паразитного пропускания прямого излучения, значительное уменьшение вклада боковых лепестков в аппаратную функцию [1,2]. Особенно это важно при использовании таких АОМ для передачи изображения, поскольку в двойных монохроматорах существенно снижаются также и хроматические искажения. Однако при этом за счет дополнительных элементов уменьшается коэффициент передачи монохроматора. Повышение коэффициента передачи монохроматоров АО спектрометров, особенно монохроматоров для передачи изображения, - важная и актуальная задача. Эта задача обычно решается несколькими способами - увеличением входной апертуры, увеличением угла зрения, качественным просветлением всех оптических элементов. Однако этот путь практически исчерпан. Нами предложен способ увеличения светосилы двойного АОМ за счет оригинальной конструкции акустооптической ячейки (АОЯ), в которой функции входного и выходного поляризаторов выполняют отражающие грани самой АОЯ, что приводит к уменьшению оптических потерь.

1. Идея широкоугольных неколлинеарных АО фильтров была предложена в работе [3] и широко используется при изготовлении устройств с большой угловой апертурой. На рис. 1 представлены геометрия взаимодействия и обычная конструкция АОЯ на основе кристалла парателлурита.

В одноосных кристаллах, к которым принадлежит и парателлурит, область существования неколлинеарных широкоугольных акустооптических фильтров (АОФ) определяется углом распространения световой волны $\theta$ и направлением волнового вектора звуковой волны $\gamma$, задаваемыми относительно кристаллографических осей (рис. 1). Угол $\theta$ может задаваться в широких пределах, формально от $0^{\circ}$ до $90^{\circ}$, угол $\gamma$ определятся углом $\theta$ и варьируется для кристалла парателлурита от $0^{\circ}$ до примерно $19^{\circ}$, что было показано в работах $[4,5]$.

Ранее была предложена такая конфигурация АОЯ $[6,7]$, в которой одна из граней кристалла парателлурита выполняет функции поляризатора. Суть этой идеи представлена на рис. 2.

При падении светового луча на грань $A$ ход лучей после отражения зависит от направления распространения падающего светового пучка относительно оптической оси кристалла (оси 001), величин обыкновенного $\left(n_{o}\right)$ и необыкновенного $\left(n_{e}\right)$ коэффициентов преломления и определяется законами отражения света в анизотропной среде. На рис. 3 приведены результаты расчета угла между обыкновенным и необыкновенным пучками на выходе из АОЯ $\left(\varphi_{o}\right)$ при падении входного излучения на отражающую поверхность $A$ под углом $45^{\circ}$ (кривая 1 ). Кривая 2 - это зависимость угла между необыкновенным пучком, продифрагировавшим из обыкновенного пучка, и необыкновенным пучком падающего излучения $\left(\varphi_{e}\right)$. Как и следовало ожидать, при отражении прямого излучения, распространяющегося под углом $45^{\circ}$ к оптической оси, расщепления обыкновенной и необыкновенной составляющих светового пучка не происходит, при распространении падающего излучения под углом $0^{\circ}$ и $90^{\circ}$ к оптической оси угол расщепления максимальный. При АО дифракции излучения из обыкновенного пучка в необыкновенный происходит дополнительное угловое отклонение этой части излучения (пучок 3 , рис. $2, b)$.

Ясно, что предложенная схема АОФ будет эффективной, если угол $\varphi_{e}$ будет больше половины угловой апертуры поляризатора. У поляризатора Глана с воздушным зазором, сделанного из кальцита, угловая апертура около $8^{\circ}$, и как видно из графика (рис. 3), для этой 

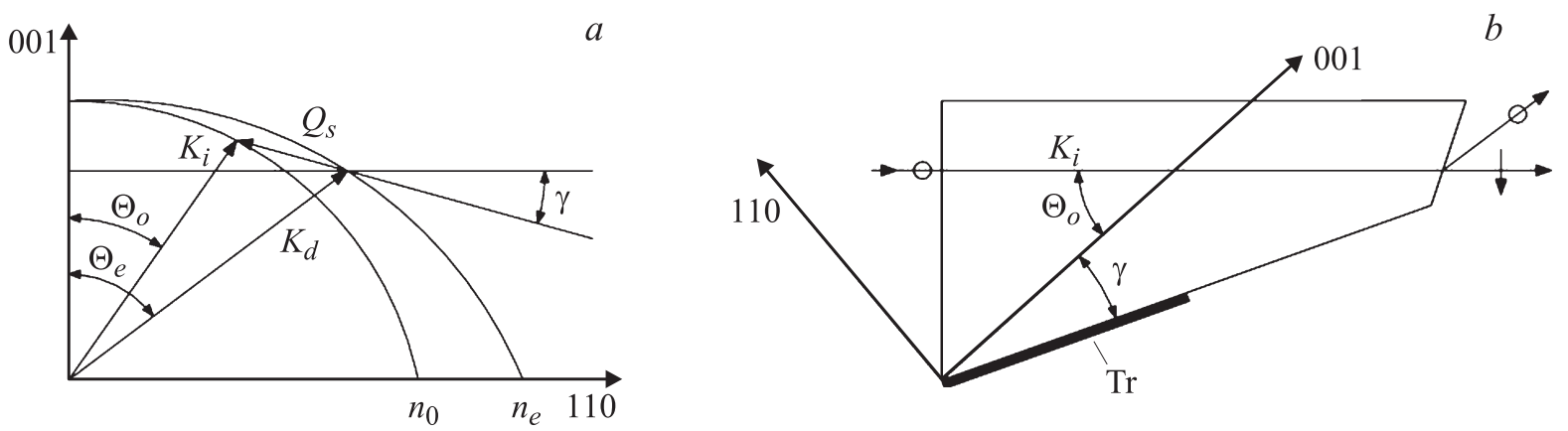

Рис. 1. $a$ - геометрия акустооптического взаимодействия, $b-$ конструкция АОЯ. $K_{i}, K_{d}, Q_{s}-$ волновые векторы падающей дифрагированной световых волн и звуковой волны, 001 и $110-$ кристаллографические направления, $n_{o}$ и $n_{e}-$ коэффициенты преломления, $\operatorname{Tr}$ - ультразвуковой преобразователь, знаки $\uparrow$ и о указывают состояние поляризации.
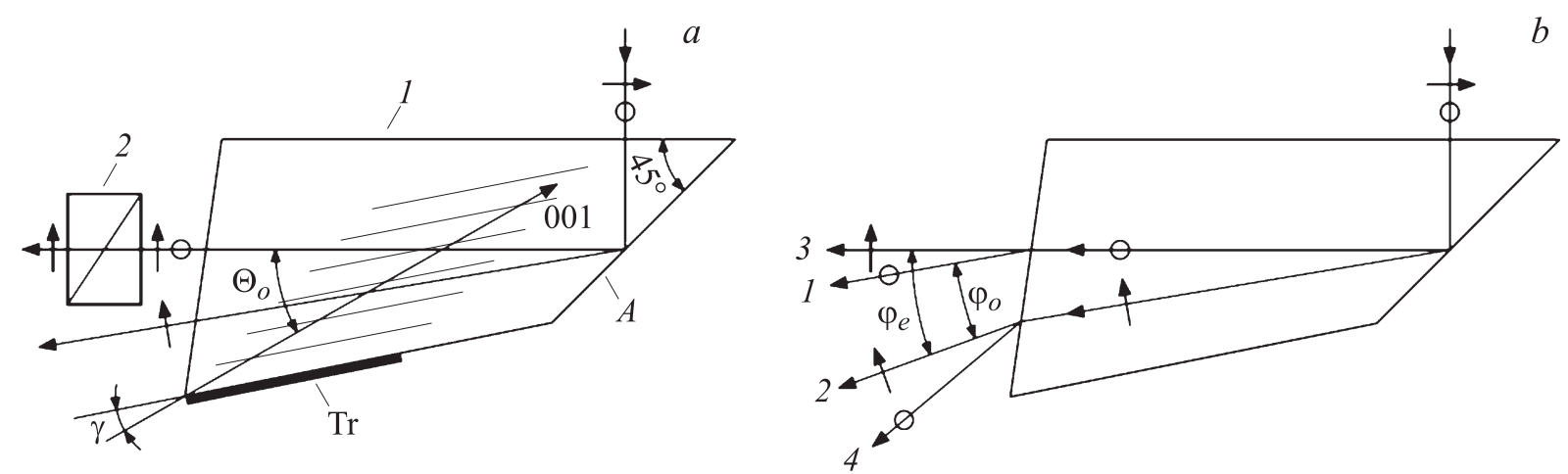

Рис. 2. АОМ: $a-$ схема конструкции, $\gamma$ и $\theta-$ углы распространения звукового и светового пучков; $1-\mathrm{AOЯ,} 2-$ поляризатор, $A$ - грань АОЯ, 001 - оптическая ось кристалла; $b$ - распространение световых пучков, 1,2 - падающий обыкновенный и необыкновенный пучки, 3,4 - дифрагированные обыкновенные и необыкновенные пучки, $\varphi_{o}, \varphi_{e}$ - углы между пучками 1,2 и $1,3$.

схемы следует использовать АОФ с углом $\theta_{o}$ менее $55^{\circ}$. Как правило, именно такие АОЯ и используются в различных конструкциях.

На рис. 4 представлены спектральные зависимости углов $\varphi_{e}$ и $\varphi_{o}$. Видно, что угол $\varphi_{e}$ уменьшается с ростом длины волны излучения, но до конца спектрального диапазона пропускания парателлурита остается достаточным для использования предложенной схемы разведения оптических пучков. Более того, при длине волны света больше $1 \mu \mathrm{m}$ величина угла между продифрагировавшим и падающим необыкновенным пучками практически не зависит от длины волны света, что важно для практического использования.

2. Конструкцию АОЯ, описанную выше, удобно использовать для создания двухкристальных монохроматоров, которые обладают существенно лучшими характеристиками передаточной функции по сравнению с однокристальными АОМ.

Обычная схема двухкристального монохроматора представлена на рис. 5, $a$. В ней используются три кристаллических поляризатора Глана с воздушным зазором. Эти поляризаторы вносят около $40 \%$ потерь для осевого пучка, а при отклонении излучения от оси более чем на $4^{\circ}$ пропускание становится равным нулю. В предложенной схеме (рис. $5, b)$ используется только

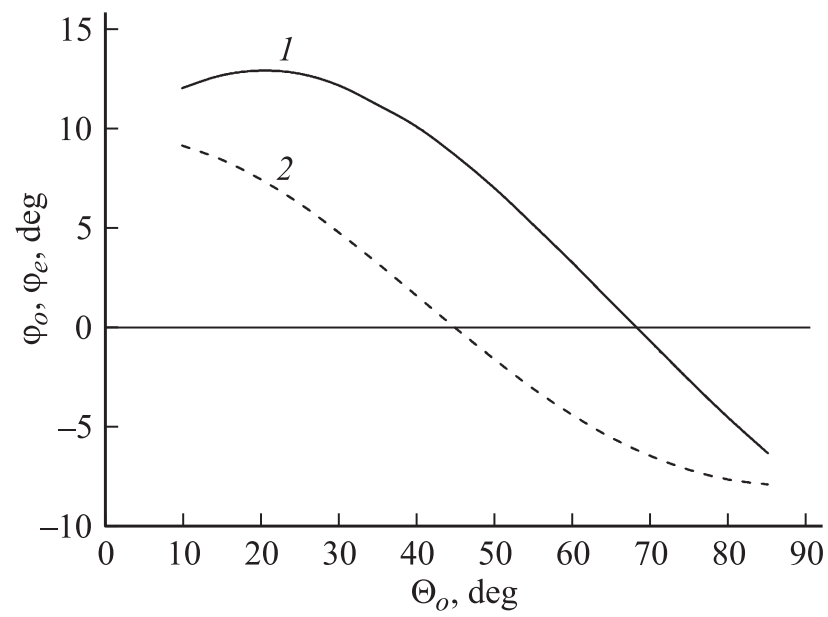

Рис. 3. Расчетные зависимости $(\lambda=633 \mathrm{~nm})$ угла $\varphi_{e}(1)$ и угла $\varphi_{o}(2)$ от направления падающего обыкновенного луча $\left(\theta_{o}\right)$.

один поляризатор, он отсекает три пучка из четырех, выходящих из первой АОЯ, и пропускает только продифрагировавший необыкновенный пучок (3 на рис. 2,b). Функции входного и выходного разводящих поляризато- 
Таблица 1.

\begin{tabular}{|c|c|c|}
\hline Характеристика & AOM 1 & AOM 2 \\
\hline Параметры АОЯ & $\gamma=6^{\circ}$ и $\theta_{o}=12.3^{\circ}$ & $\gamma=7.1^{\circ}$ и $\theta_{o}=14.4^{\circ}$ \\
\hline Частота синхронизма при $\lambda=633 \mathrm{~mm}$ & $66.7 \mathrm{MHz}$ & $80.2 \mathrm{MHz}$ \\
\hline Длина УЗП & $8 \mathrm{~mm}$ & $14 \mathrm{~mm}$ \\
\hline Ширина аппаратной функции & $410 \mathrm{KHz}(3.9 \mathrm{~nm})$ & $245 \mathrm{KHz}(1.94 \mathrm{~nm})$ \\
\hline Спектральный диапазон & $440-760 \mathrm{~nm}$ & $450-950 \mathrm{~nm}$ \\
\hline Частотный диапазон возбуждения, КСВ & $106-53 \mathrm{MHz}, 2.5$ & $127-49 \mathrm{MHz}, 3.5$ \\
\hline $\begin{array}{l}\text { Максимальный коэффициент пропускания } \\
\text { для линейно поляризованного излучения } \\
\text { на длине волны } 633 \mathrm{~nm}\end{array}$ & $57 \%$ & $62 \%$ \\
\hline Апертура & $7 \mathrm{~mm} \times 3^{\circ}$ & $6 \mathrm{~mm} \times 3^{\circ}$ \\
\hline $\begin{array}{l}\text { Угол разведения пучков дважды } \\
\text { продифрагированного излучения } \\
\text { и излучения, продифрагировавшего } \\
\text { один раз на выходе монохроматора }\end{array}$ & $12^{\circ}$ & $12.6^{\circ}$ \\
\hline
\end{tabular}

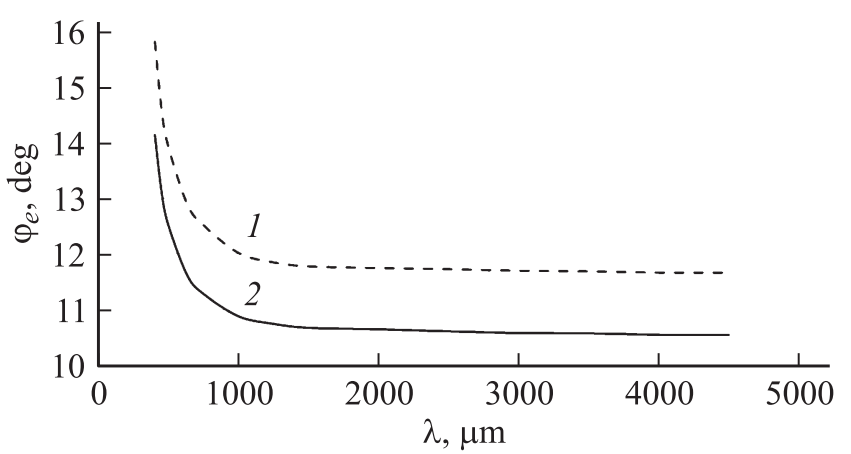

Рис. 4. Расчетные спектральные зависимости $\varphi_{e}$ для АОФ с различными $\theta .1-\theta_{e}=16.4^{\circ}, 2-\theta_{e}=34^{\circ}$.

ров выполняют грани $A$ АОЯ. В результате обеспечивается большее пропускание как осевого излучения, так и составляющих светового пучка, распространяющихся под углом к оптической оси.

Нами были изготовлены два монохроматора с АОЯ, в которых роль разводящих поляризаторов выполняла одна из граней. В одном случае использовались АОЯ с углами $\gamma=6^{\circ}$ и $\theta_{o}=12.3^{\circ}$, в другом случае использовались АОЯ с углами $\gamma=7.1^{\circ}$ и $\theta_{o}=14.4^{\circ}$. В таблице представлены некоторые технические характеристики этих монохроматоров.

Следует отметить, что угол разведения световых пучков на выходе второй АОЯ составляет около $12^{\circ}$, что значительно больше входной угловой рабочей апертуры монохроматора $\left(3^{\circ}\right)$. Такое пространственное разделение световых пучков дает возможность обойтись без поляризатора также и на выходе из монохроматора.

На рис. 6 представлен спектрометр изображений, предназначенный для установки на микроскоп, состоящий из $\mathrm{AO}$ монохроматора (АОЯ $\gamma=6^{\circ}$ и $\theta_{o}=12.3^{\circ}$ ), ВЧ блока управления и видеокамеры. У монохроматора снята крышка и видно расположение центрального по- ляризатора и платы ВЧ согласования АОЯ. На передней панели ВЧ блока находятся USB разъем подключения спектрометра к компьютеру, разъем для питания и индикаторы включения. ВЧ блок формирует сетку дискретных ВЧ частот и усиливает их по мощности до уровня, необходимого для обеспечения высокого коэффициента передачи монохроматора в спектральном диапазоне. ВЧ драйвер монохроматора состоит из синтезатора частоты и усилителя мощности. Синтезатор частоты выполнен по схеме прямого синтеза на микросхеме AD9954 с управлением через микропроцессор AT91SAM7. Усилитель ВЧ мощности двухканальный и с максимальной выходной мощностью $2 \cdot 0.7 \mathrm{~W}$, которая превышает требуемую для 70\% эффективности АОФ во всем спектральном диапазоне. Регулировка уровня ВЧ мощности осуществляется как встроенным в синтезатор ЦАП, так и дополнительным 14-разрядным ЦАП, управляемым
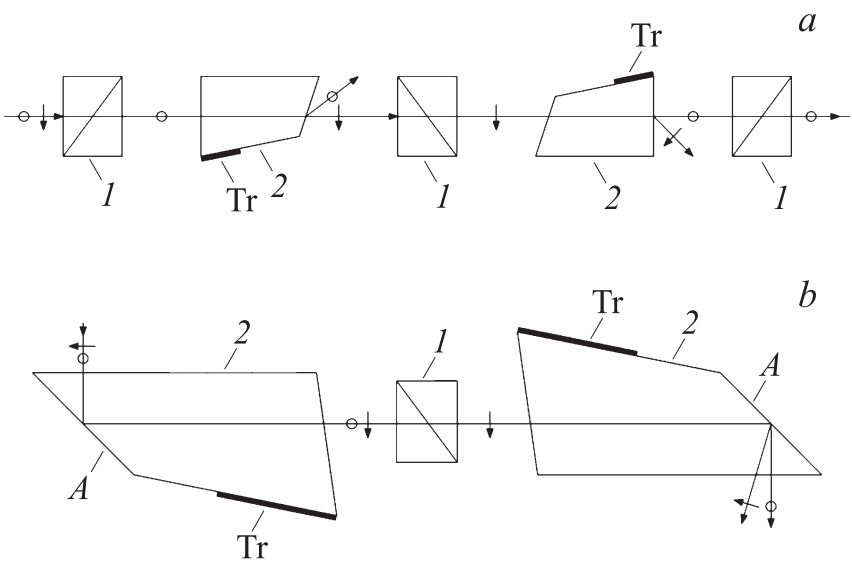

Pис. 5. $a-$ схема „обычного“ двухкристального монохроматора [8], $b-$ схема „безполяризационного“ монохроматора: 1 - поляризаторы, 2 - АОЯ, $A$ - грани, выполняющие роль разводящего поляризатора. 


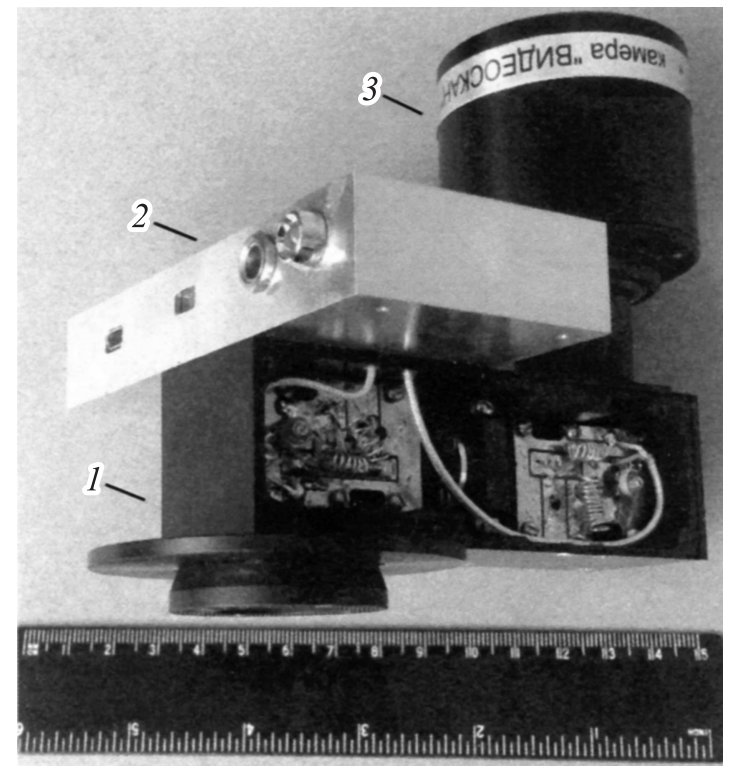

Рис. 6. Фотография спектрометра изображений с адаптером для установки на оптический микроскоп (АОМ со снятой крышкой): 1 - АОМ, $2-$ ВЧ драйвер, управляемый через USB-порт, 3 - видеокамера.

микропроцессором. На выходе синтезатора и усилителя стоят фильтры верхних частот шестого порядка.

Исследования показали, что при использовании такого монохроматора как насадки на микроскоп обеспечивается изображение с количеством элементов $250 \times 250$. Качество изображения будет существенно лучше при работе монохроматора в параллельных световых пучках, но для этого необходимо использовать два объектива: входной и выходной. Измеренный коэффициент пропускания АОМ для линейно поляризованного лазерного пучка оказался около 60\%, что примерно в полтора раза больше, чем у АОМ обычного двухкристального монохроматора с входным и выходным поляризаторами [8]. Величина боковых лепестков аппаратной функции монохроматоров не превышала $1.2 \%$ от максимума аппаратной функции.

\section{Заключение}

Исследованы две конструкции светосильного „безполяризационного“ двухкристального АОМ с различным значением параметров АОЯ.

Для обеих конструкций подтверждена возможность создания светосильного „безполяризационного двухкристального АОМ для получения изображений объекта в различных спектральных интервалах.

Созданные монохроматоры из-за отсутствия поляризаторов обладают примерно в полтора раза бо́льшим коэффициентом пропускания света для осевого пучка по сравнению с традиционными.
Такие монохроматоры, кроме того, имеют значительно меньший вес и габариты, оказываются проще в настройке и, как следствие, имеют меньшую стоимость.

Авторы выражают благодарность В.М. Епихину за интерес к работе и полезные замечания, М.В. Жогуну за помощь в оформлении работы. Работа частично поддержана грантом РФФИ № 15-08-08696.

\section{Список литературы}

[1] Мазур М.М., Пожсар В.Э., Пустовойт В.И., Шорин В.Н. // Успехи современной радиоэлектроники. 2006. № 10. С. 1930.

[2] Мазур М.М., Судденок Ю.А., Шорин В.Н. // Письма в ЖТФ. 2014. Т. 40. Вып. 4. С. 56-62.

[3] Chang I.C. // Appl. Phys. Lett. 1974. Vol. 25. P. 370-372.

[4] Chang I.C. // Ellectron. Lett. 1975. Vol. 11. N 25-26. P. 617618.

[5] Епихин В.М., Визен Ф.Л., Пальцев Л.Л. // ЖТФ. 1987. Т. 57. Вып. 10. С. 1910-1917.

[6] Пат. РФ № 2388030. Неколлинеарный акустооптический фильтр. М.М. Мазур, В.И. Пустовойт. 2010. БИ. № 12.

[7] Мазур М.М., Пустовойт В.И. // Тр. межд. конф. Прикладная оптика-2010. СПб. 2010. С. 229-231.

[8] Епихин В.М., Кияченко Ю.Ф., Мазур М.М., Мазур Л.И., Пальцев Л.Л., Судденок Ю.А., Шорин В.Н. // Физические основы приборостроения. 2013. Т. 2. № 4. С. 116-125. 